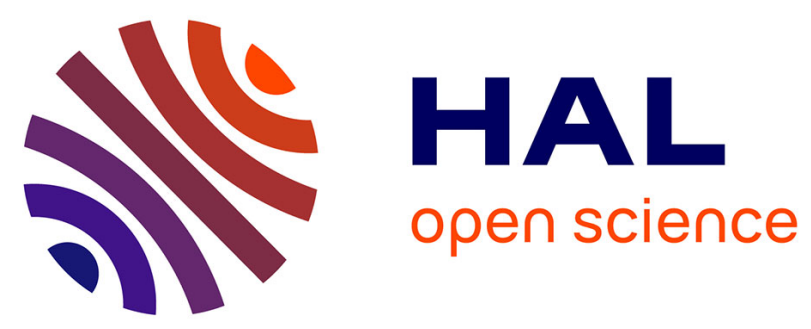

\title{
The role of graft reperfusion sequence in the development of non-anastomotic biliary strictures following orthotopic liver transplantation: A meta-analysis
}

Mohamed Bekheit, Matteo Catanzano, Stuart Shand, Irfan Ahmed, Elsaid Elkayal, Gihan Mohamed Shehata, Adel Zaki

\section{To cite this version:}

Mohamed Bekheit, Matteo Catanzano, Stuart Shand, Irfan Ahmed, Elsaid Elkayal, et al.. The role of graft reperfusion sequence in the development of non-anastomotic biliary strictures following orthotopic liver transplantation: A meta-analysis. Hepatobiliary and Pancreatic Diseases International, 2019, 18, pp.4 - 11. 10.1016/j.hbpd.2018.12.003 . hal-03486423

\section{HAL Id: hal-03486423 \\ https://hal.science/hal-03486423}

Submitted on 20 Dec 2021

HAL is a multi-disciplinary open access archive for the deposit and dissemination of scientific research documents, whether they are published or not. The documents may come from teaching and research institutions in France or abroad, or from public or private research centers.
L'archive ouverte pluridisciplinaire HAL, est destinée au dépôt et à la diffusion de documents scientifiques de niveau recherche, publiés ou non, émanant des établissements d'enseignement et de recherche français ou étrangers, des laboratoires publics ou privés.

\section{(ㄷ)(1) $\$$}

Distributed under a Creative Commons Attribution - NonCommerciall 4.0 International 


\section{Manuscript Type: Meta-analysis}

Running title: Graft reperfusion sequence in non-anastomotic biliary strictures

The role of graft reperfusion sequence in the development of non-anastomotic biliary strictures following orthotopic liver transplantation: A meta-analysis

Mohamed Bekheit ${ }^{1,2,3,4,5, *}$, Matteo Catanzano ${ }^{5}$, Stuart Shand ${ }^{3}$, Irfan Ahmed ${ }^{3,5}$, ELSaid ELKayal $^{6}$, Gihan Mohamed Shehata ${ }^{2}$, Adel Zaki ${ }^{2}$

(Bekheit M, Catanzano M, Shand S, Ahmed I, ELKayal E, Mohamed Shehata G, Zaki A) Aberdeen, $U K$

\section{Author Affiliations:}

1. University of Paris-Sud, Center of Liver Surgery and Transplantation, Paul Brousse Hospital, Villejuif Cedex, France.

2. Medical Research Institute, University of Alexandria, Alexandria, Egypt

3. HBP Surgery Unit Department of Surgery, Aberdeen Royal Infirmary, Aberdeen, UK

4. Department of Surgery, Elkabbary General Hospital, Alexandria, Egypt

5. University of Aberdeen, Aberdeen, UK

6. Department of Surgery, Alexandria Main University Hospital, Faculty of Medicine, Alexandria, Egypt

* Corresponding Author: Mohamed Bekheit, MD, Department of Surgery, Aberdeen Royal Infirmary, Aberdeen, UK (Tel: +44-0-7729385485; Email:

Dr_mohamedbekheit@hotmail.com)

\section{Received 28 June 2018}

Accepted 22 November 2018 
Contributors: BM, MSG and ZA designed the study. BM and CM searched the literature. $\mathrm{BM}$ systematically reviewed the literature. $\mathrm{BM}$ and $\mathrm{CM}$ extracted the data. $\mathrm{BM}, \mathrm{CM}, \mathrm{AI}, \mathrm{EE}$ and ZA analyzed the data. All authors contributed to the design and interpretation of the study and to further drafts. BM is the guarantor.

Funding: None.

Ethical approval: Not needed.

Competing interest: No benefits in any form have been received or will be received from a commercial party related directly or indirectly to the subject of this article.

Background: Liver transplant is a potential cure for liver failure and hepatic malignancy but there are many techniques which have been described for vascular reconstruction. This study was to compare the prevalence of non-anastomotic biliary stricture and other surgical complications based on Clavien-Dindo scoring system, in initial portal reperfusion (sequential) versus simultaneous or initial artery reperfusion.

Methods: Meta-analysis of published studies comparing the outcomes of both techniques was carried out. Data search was conducted across the major databases and studies were selected under the guidance of the Cochrane guidelines for systematic reviews and metaanalysis.

Results: Seven studies were included to address the primary and the secondary outcomes. No statistical difference was found in the incidence of non-anastomotic biliary strictures $(\mathrm{OR}=0.40 ; P=0.14)$, regardless of reperfusion technique. The pooled estimate of the ClavienDindo grading of complications was not significantly different between the techniques, though Clavien-Dindo II complications were higher in the simultaneous or initial artery reperfusion group than the initial portal reperfusion group (OR 2.73; $P=0.01$ ). Similarly, 
there was no difference in the operative time, hospital stay and other outcomes addressed in this report.

Conclusions: The available evidence suggests that there is no significant difference demonstrated in the rate of non-anastomotic biliary strictures or other complications, between the two techniques, except for Clavien-Dindo II complications.

Key words: liver transplantation; organ transplantation; liver surgery; rejection

\section{Introduction}

Liver transplantation is considered as a potential cure for end stage liver failure and primary hepatic malignancy [1]. The outcome of this procedure has significantly improved over the past decades [2], with significant improvement of survival by approximately $30 \%$ at 1, 3, and 5 years [3]. However, biliary complications remain relatively high (up to 30\%) [4].

There are numerous techniques for vascular reconstruction described for liver transplantation [5]. The variation in surgical technique is thought to influence the perioperative outcome [6]. Revascularization sequence is also considered a potential source of biliary complications after liver transplantation [7]. The link between reperfusion sequence, biliary strictures and graft loss following liver transplantation is not clear in the literature, despite its high importance and the biliary complications being a significant risk factor for graft loss [8]. Initial portal reperfusion (IPR) is the most commonly practiced sequence [8]. However, since the bile ducts seem to be solely dependent on the hepatic artery for their blood supply [9], it is thought that this technique would lead to the increased biliary warm ischemia time and increase the risk of ischemic biliary complications [10].

In the absence of arterial blood supply to the bile duct while the portal perfusion is restored; ischemic bile injuries may develop in the form of non-anastomotic stricture [11]. It 
has been reported that contemporaneous perfusion could be useful in reducing nonanastomotic type biliary injuries [12]. However, this finding was not observed in a different study [13]. Although investigated further, this important question, whether the initial artery reperfusion (IAR)/simultaneous reperfusion has an advantage over IPR or not, remains unanswered.

The primary objective of this study was to compare the incidence of non-anastomotic biliary stricture, in both techniques. The secondary objective was to examine the difference in the incidence rate of surgical complications, according to Clavien-Dindo scoring system, between both techniques (excluding the non-anastomotic biliary stricture) [14]. Additionally, the length of hospital stay, cold ischemia time and the incidence of reperfusion injury were looked at in this study.

\section{Methods}

\section{Study design}

The study design is a systematic review and meta-analysis of the eligible studies according to predefined guidelines provided by the Cochrane Collaboration (2008).

\section{Search strategy}

$\mathrm{BM}$ and $\mathrm{CM}$ searched independently for all relevant published research to identify studies from the following databases: Cochrane database, Web of Science, Trip database, PubMed/Medline, Ovid database, and Embase. The search terms used in this review were (Sequential OR simultaneous OR contempor*) AND (reperfusion OR perfusion) AND (liver transplant*). All the articles that were found suitable for inclusion were cross-referenced to ensure inclusion of the eligible studies. Detailed search strategies, Boolean operators, different search techniques, filters, and limits were documented in detail in Table 1. A 
PRISMA flow chart was used to illustrate the identification, screening, and inclusion of relevant articles (Fig. 1). The search was last updated in December 2016.

\section{Inclusion and exclusion criteria}

Randomized controlled trials (RCTs) comparing both approaches were included. Other comparative studies were included, provided that studies were abiding by a clear PICO format and reported the outcome of interest.

No publication date restriction was set. The search was primarily in English. However, studies in French and Italian languages were not excluded and were considered if they met inclusion criteria. Translation was to be provided by the authors' team.

Studies which satisfied the following criteria were included: 1) Adult human recipients of full liver grafts; 2) Studies comparing contemporaneous/simultaneous arterial and portal reperfusion to conventional sequential portal then arterial reperfusion or comparing sequential initial arterial then portal reperfusion to conventional sequential initial portal then arterial reperfusion. The inclusion of both initial arterial reperfusion or the simultaneous reperfusion is justified by the theory behind the injury in both cases, which is the relative biliary hypoxia from a delayed artery perfusion in a warm condition induced by portal perfusion; 3) All RCTs and comparative studies (both prospective and retrospective) comparing the contemporaneous reperfusion versus the standard sequential reperfusion (portal first); 4) Describing the primary or the secondary outcomes described above, regardless of whether the study in question regarded them as their primary outcome or not.

The operational definition of the techniques under investigation were as follows: 1) Sequential reperfusion was identified when the anastomosed portal vein was declamped before the start of the arterial anastomosis and 2) Simultaneous reperfusion was identified when the portal vein and the hepatic artery anastomoses were declamped after completion of both anastomoses without prior hepatic reperfusion through the portal vein. Initial arterial 
reperfusion was considered with this group based on the underlying pathophysiological hypothesis.

The outcomes of interest were defined as follows: 1) Non-anastomotic biliary strictures were one or more focal areas of narrowing of the bile ducts proximal to a biliary anastomosis regardless any anastomotic stricture; 2) Duration of hospital stay; 3) Cold ischemia time or the time from perfusion of the graft with the preservative fluid until the reinstitution of the blood flow; 4) Reperfusion injury or damage to the transplanted liver caused by cold or warm ischemia (keeping the liver at body temperature after its blood supply has been reduced or cut-off).

Exclusion criteria involved studies that: 1) Compared to a different technique than those of interest, 2) were single arm, 3) were not on human subjects, 4) had incomplete outcome data; judged by the review authors, and 5) were in the Non-English languages (apart from French and Italian).

\section{Data extraction}

$\mathrm{BM} \& \mathrm{CM}$ were responsible for conducting the search and retrieval of the database of full-text studies. Both authors were independently responsible for the selection of studies and to list excluded studies with reasons for exclusion. A third author's opinion was sought to resolve any conflict regarding studies inclusion and quality scoring.

The extracted data were the following:1) Justification for inclusion and exclusion of studies; 2) year of publication; 3) Sample size; 4) Outcome data: no-anastomotic biliary stricture, other complications and grading (Clavien-Dindo I, II, III, and IV); and 5) methodological quality assessment.

\section{Data transformation}


All reported complications were transformed to the corresponding grade of ClavienDindo score as closely as possible. Studies that reported Clavien-Dindo scores, scores were treated as was.

Analysis of each grade complication frequency was conducted separately, and then a pooled frequency estimate was calculated.

\section{Assessment of methodological quality}

The methodological quality of the trials was assessed without masking the trial names, according to the guidance given in the Cochrane handbook for systematic reviews of interventions [15] to evaluate the risk of bias associated with overestimation of intervention effects [16-19], and West score was adopted [20].

\section{Statistical analysis}

The meta-analysis was carried out as close as possible to the recommendations of the Cochrane Collaboration [15] using the Comprehensive meta-analysis software (CMA) V2 (Biostat. Inc., Eaglewood, New Jersey, USA) for the statistical analysis. For continuous variables, the standardized difference of means and its standard error was calculated. We elected to calculate the "Hedges' g" and its standard error for both types of data to represent the overall (pooled) effect estimate when including all the parameters expressing the outcomes. For data describing central tendency in median and range instead of mean and standard deviation, we converted these values into mean and standard deviation, when necessary, using methods suggested by Hozo et al. [21].

A random-effects model [22] was used due to heterogeneity in study design [23]. We measured the quantity of heterogeneity (within-study) [24]. We considered an $\mathrm{I}^{2}$ of $30 \%$ or more represents heterogeneity. Among studies, heterogeneity was expressed by Tau- 
squared values [25]. A one-study-removed approach was used to evaluate the influence of individual studies on the $95 \%$ CI of the heterogeneity estimates [25].

Since the primary outcome could require a long time to manifest, we planned to perform the analysis on an intention-to-treat basis [26] for patients who underwent revision of their vascular anastomosis; whenever possible. For that purpose, multiple imputation analysis was considered in SPSS version 22 (IBM Inc., Chicago, IL, USA). Otherwise, the 'available case analysis' was adopted. In the case of 'zero-event' trials in statistically significant outcomes, a sensitivity analysis with and without empirical continuity correction factors was planned for as suggested by Sweeting et al. [27]. We decided to conduct sensitivity analyses based on study design, date of publication and quality assessment. We arbitrarily chose 2005 as the cut-off to differentiate 'older' studies from 'newer' ones. We additionally, arbitrarily chose a West score of 30 as the quality score, to separate 'higher' quality studies from 'lower' quality ones. Meta-regression was not conducted since there was no sufficient number of studies that addressed the primary outcome [15]. We used a funnel plot to explore bias $[27,28]$ based on a standard error on the vertical axis as recommended by Sterne et al. [29]. We also performed linear regression described by Egger et al. to determine the funnel plot asymmetry [30].

\section{Results}

A total of 384 studies were yielded. Seven studies were ultimately included in analyses following the selection ladder described in Fig. 1. The study included 685 patients.

Seven studies reported the prevalence of non-anastomotic biliary stricture (NABST) $[13,31-36]$. The estimate of the within-study variation was not significant $(\mathrm{Q}=13.12, P=0.14$, $\left.\mathrm{I}^{2}=54 \%\right)$ and the estimate heterogeneity revealed a Tau-squared=1.44, $\mathrm{SE}=1.59$. We examined the random effect model which assumed the null hypothesis $(\mathrm{OR}=0.40 ; 95 \% \mathrm{CI}$ : 
0.12-1.37; $P=0.14$ ) (Fig. 2A). A subgroup analysis for study type looking at RCTs showed an even higher $\mathrm{OR}(\mathrm{OR}=0.61 ; 95 \% \mathrm{CI}$ : $0.05-7.19 ; P=0.69)$ compared to one looking at case series $(\mathrm{OR}=0.31 ; 95 \% \mathrm{CI}: 0.06-1.50 ; P=0.15)$ or combined (as above) (Fig. 2D), but none were statistically significant. An additional analysis was carried out for date of publication. Studies published since 2005 had an OR=0.42 (95\% CI: $0.05-3.55 P=0.43$ ) and those published before 2005 had an $\mathrm{OR}=0.40$ (95\%CI: 0.10-1.55 $P=0.19$ ) (Fig. 2C). Finally, subgroup analysis by quality assessment, looking at studies with a West score of 30 and above [15,20] (Table 2) $(\mathrm{OR}=0.3695 \% \mathrm{CI}: 0.03-4.17 \quad P=0.41)$ was carried out (Fig.2B). There were no statistically significant differences between IPR and IAR/simultaneous reperfusion prevalence of NABST (Fig. 2).

Only one study reported control for the main confounding factor, which is arterial thrombosis. The pooled all grades Clavien complication score were similar in both groups $\left(\mathrm{OR}=0.77, P=0.061 ; \mathrm{Q}=2.86, P=0.61, \mathrm{I}^{2}=0 \%\right.$ and the Tau squared $\left.=0\right)($ Fig. $3 \mathrm{~A})$. Clavien II grade score was reported in 3 studies [13,32,35]. The Clavien II complications were higher in the IAR group than in the IPR group (OR=2.73; 95\% CI: $1.33-5.62 ; P=0.006),(Q=1.26$, $\mathrm{I}^{2}=0 \%, P=0.53$, Tau squared $=0$ ) (Fig. 3B). While no study reported on Clavien III grade of complications, 3 studies reported on Clavien IV grade complications [13,31,35] (Fig. 3C). IAR had lower incidence of Clavien grade IV complications than in IPR $(\mathrm{OR}=0.31, P=0.12)$ $\left(\mathrm{Q}=2.61, \mathrm{I}^{2}=23 \%, P=0.27\right.$, Tau squared $\left.=0.42 ; \mathrm{SE}=1.78\right)$.

Both techniques offered an equal cold ischemia time (Hedges' $\mathrm{g}=0.04, P=0.67, \mathrm{Q}=4.70$, $P=0.45, \mathrm{I}^{2}=0 \%$ and Tau squared $=0$ ). The length of hospital stay was reported in one study [31]. There was no difference in the length of hospital stay in both techniques (Hedges' $\mathrm{g}=0.01, P=0.69, \mathrm{Q}=2.63, P=0.10)$.

Only one study [31] reported the time from implantation to reperfusion, which was equal in both techniques $(P=0.61)$. Similarly, one study reported the lactate level, and it was 
equal in both groups $(P=0.95)$. The operative time was reported in 3 studies $[34,35,36]$. There was significant heterogeneity between the studies $\left(\mathrm{Q}=4, P>0.05, \mathrm{I}^{2}=50 \%\right.$. The Tau squared=0.04; $\mathrm{SE}=0.08$ ). There was no significant difference in the operative time (Hedge's $\mathrm{g}=0.02, P=0.90)$.

The prevalence of portal vein complications was reported in 2 studies [13,31]. There was no significant difference in the incidence of portal venous complications between the two techniques $\left(\mathrm{OR}=0.7, P=0.73, \mathrm{Q}=0.44, P=0.51\right.$ and $\mathrm{I}^{2}=0 \%$, Tau squared $\left.=0\right)$.

Four studies reported the prevalence of primary graft non-functioning [13,31,34,35]. There was no significant difference in the incidence of primary graft non-functioning between the two techniques $(\mathrm{OR}=0.8, P=0.70)$. There was no significant heterogeneity among studies $\left(\mathrm{Q}=1.09, P=0.7, \mathrm{I}^{2}=0 \%\right.$ and Tau-squared $\left.=0\right)$.

Mortality was reported in 6 studies [31-33,35,36,37]. No significant difference in the allcause mortality between the two techniques was observed ( $\mathrm{OR}=0.57, P=0.0 .25)$. No significant heterogeneity was observed among studies that reported mortality $(\mathrm{Q}=5.3$, $P=0.25, \mathrm{I}^{2}=0 \%$ and Tau squared=0). Similarly, there was no difference between the two techniques in the operative mortality $(\mathrm{OR}=0.92, P=0.94)$, which was reported in 1 study [31]. There was no difference in the transfusion requirement between both techniques $(\mathrm{OR}=0.84$, $P=0.60)$. There was no significant heterogeneity among studies $\left(\mathrm{Q}=6.75, P=0.08, \mathrm{I}^{2}=55.57 \%\right.$, and Tau squared $=0.24$, ). The quality scores of the included studies are given in Table 3 . The visual depiction of the publication bias is shown in Fig. 4.

\section{Discussion}

Based on these results, we could not found the significant difference between IAR and IPR in the development of non-anastomotic biliary strictures. Two studies $[35,36]$ reported a statistically significant lower prevalence of NABST with IAR/simultaneous reperfusion. 
Three studies [31,32,34] showed a non-statistically significant difference, but favoured IAR/simultaneous reperfusion compared to IPR. The non-statistically significant difference in these studies could be attributed to their underpowered design. The remaining two studies $[13,33]$ demonstrated a non-statistically significant difference and favoured IPR.

Previous study [10] attempted to document a pathophysiological hypothesis to support the idea that IAR/Simultaneous arterial reperfusion would reduce the risk of NABST. They found that 60 minutes of delay between the portal and arterial reperfusion was an independent risk for the development of severe biliary complications [10]. In an animal model, Zhu et al. linked the delay in arterial reperfusion (secondary warm ischemia) to the microvascular thrombi in peribiliary arterial plexus [40]. Changes in the pulmonary microarchitecture were also documented with the delay in arterial reperfusion [41]. This could explain the increased pulmonary complications rate found with larger grafts, given the technical challenge in these cases that could delay arterial reperfusion [42].

One of the most significant shortcomings of the available studies is the lack of data on the delay time between the portal and the arterial reperfusion, which might have highlighted a particular trend. Among the included studies that addressed this outcome, only the study by Lu et al. [35] showed a significant advantage of the simultaneous reperfusion technique. This might be related to their larger sample size. The delay time in the IPR group was defined as above 10 minutes, while reperfusion was resumed in the simultaneous group within only one minute delay between the portal vein and the hepatic artery. This highlights the importance of minimizing the length of the delay time. However, one limitation of this study was its retrospective nature.

The presence of arterial complications, including arterial thrombosis, in the perioperative period, being the most important confounding factor, was only documented in one study [32]. Therefore, it was difficult to interpret its effect, despite our attempts at 
extracting separately the incidence of NABST in patients with and without arterial thrombosis. Additionally, the reperfusion syndrome could be a major confounding factor.

There was no difference in the overall complication rates in both groups. The Clavien grade II complication rate was higher in the IAR/simultaneous reperfusion group. The operative time, the cold ischemia time, transfusion requirements and the hospital stay were not different.

Previous publication [42] quantified the effect of the simultaneous reperfusion on the development of non-anastomotic biliary stricture, however, this review was necessary to clarify several shortcomings in those studies. A review by Wang et al. [43] included the study from Adani et al. [12], which was republished again [44] and a study from the same group that included the same group of patients within the study population [35]. Adani's study [12] included the same patients within the study population, with half the sample size of Baccarani et al. [36]. Hence this study was excluded from the final analysis as including both papers in a meta-analysis would invalidate the results and its conclusions [42].

The visual inspection of the funnel plot did not suggest a publication bias (Fig. 4). However, this is not conclusive given the small number of included studies [15]. We were not able to examine one potential study [45] since it was not possible to access its content despite many attempts of communication with national libraries, the author, and the publisher. We restricted the search language to only English, French and Italian. As the majority of the published meta-analysis, this one is not an exception from the risk of being affected by the publication bias.

The current review included the non-randomized comparative trials that fulfilled the inclusion criteria. To avoid the possible bias introduced by this inclusion we have conducted a subgroup analysis based on the study design to examine the difference in the effect size.

The common shortcoming among these studies is their low power. Hence, a non- 
significant $P$ value does not necessarily mean a no-effect. Based on the pooled estimate of the effect size from the included studies, a study that include 200 in each arm would have a power of $80 \%$ in detecting a $5 \%$ difference in the prevalence of NABST at an alpha error level of $5 \%$.

However, there remains heterogeneity and a large difference in the quality of the included studies. Therefore, interpretation of the results should be careful and the need for a single, powered, and high-quality study is still warranted. Since we have noticed that there is missing information in each of the included studies, particularly about the confounding factors, we herein propose a standard core outcome set to be considered by future studies. Analysis of the published studies suggests that most of these lesions develop in the early period of the first 18 months after transplantation [35]. Therefore, a follow-up of 18 months is proposed for future studies. Moreover, there should be a distinction between donors following cardiac versus brain death since this might influence the outcome.

In conclusion, the available evidence suggests there is no significant difference in the rate of non-anastomotic biliary strictures or other complications, between the two techniques, except for Clavien II complications, which were lower for sequential (IPR) reperfusion. However, many of these studies were underpowered and a significant degree of heterogeneity existed between them. A single high-powered, high-quality study could eliminate the impact of heterogeneity and increase the robustness of our conclusion.

\section{References}

1 Al Sebayel M, Alenazi AM, Sabbagh R, Al Ageel T, Al Enazi M, Al Bahili H, et al. Donor organ shortage crisis: a case study review of a financial incentive-based system. Transplant Proc 2014;46:2030-2035.

2 Åberg F, Gissler M, Karlsen TH, Ericzon BG, Foss A, Rasmussen A, et al. Differences 
in long-term survival among liver transplant recipients and the general population: a population-based Nordic study. Hepatology 2015;61:668-677.

3 Jain A, Reyes J, Kashyap R, Dodson SF, Demetris AJ, Ruppert K, et al. Long-term survival after liver transplantation in 4,000 consecutive patients at a single center. Ann Surg 2000;232:490-500.

4 Wojcicki M, Milkiewicz P, Silva M. Biliary tract complications after liver transplantation: a review. Dig Surg 2008;25:245-257.

5 Lladó L, Figueras J. Techniques of orthotopic liver transplantation. HPB (Oxford) 2004;6:69-75.

6 Hosein Shokouh-Amiri M, Osama Gaber A, Bagous WA, Grewal HP, Hathaway DK, Vera SR, et al. Choice of surgical technique influences perioperative outcomes in liver transplantation. Ann Surg 2000;231:814-823.

7 Panaro F, Chauvat J, Carabalona JP, Nougaret S, Bouyabrine H, Marchand JP, et al. Double arterial anastomosis in liver transplantation: is two better than one? J Gastrointest Surg 2013;17:1512-1515.

8 Manzini G, Kremer M, Houben P, Gondan M, Bechstein WO, Becker T, et al. Reperfusion of liver graft during transplantation: techniques used in transplant centres within Eurotransplant and meta-analysis of the literature. Transpl Int 2013;26:508-516.

9 Hwang S. Microcirculation of the Liver. Madoff DC, Makuuchi M ITVJ-N, editor. Venous embolization of the liver: Radiological and surgical practice. London: Springer; 2011:9-13.

10 Wang MF, Jin ZK, Chen DZ, Li XL, Zhao X, Fan H. Risk factors of severe ischemic biliary complications after liver transplantation. Hepatobiliary Pancreat Dis Int 2011;10:374-379.

11 Tawadrous MN, Zimmermann A, Zhang XY, Wheatley AM. Persistence of impaired hepatic microcirculation after nonarterialized liver transplantation in the rat. Microcirculation 2002;9:363-375.

12 Adani GL, Rossetto A, Bresadola V, Lorenzin D, Baccarani U, De Anna D. Contemporaneous portal-arterial reperfusion during liver transplantation: Preliminary results. J Transplant 2011;2011:251656.

13 Polak WG, Miyamoto S, Nemes BA, Peeters PM, de Jong KP, Porte RJ, et al. Sequential and simultaneous revascularization in adult orthotopic piggyback liver transplantation. Liver Transpl 2005;11:934-940.

14 Dindo D, Demartines N, Clavien PA. Classification of surgical complications: a new 
proposal with evaluation in a cohort of 6336 patients and results of a survey. Ann Surg 2004;240:205-213.

15 Higgins JPT, Green S. Cochrane handbook for systematic reviews of interventions. Higgins JPT, Green S, editors. Vol. 5. London: Cochrane Collaboration and John Wiley \& Sons Ltd; 2008.

16 Kjaergard LL, Villumsen J, Gluud C. Reported methodologic quality and discrepancies between large and small randomized trials in meta-analyses. Ann Intern Med 2001;135:982-989.

17 Moher D, Pham B, Jones A, Cook DJ, Jadad AR, Moher M, et al. Does quality of reports of randomised trials affect estimates of intervention efficacy reported in metaanalyses? Lancet 1998;352:609-613.

18 Schulz KF, Chalmers I, Hayes RJ, Altman DG. Empirical evidence of bias. Dimensions of methodological quality associated with estimates of treatment effects in controlled trials. JAMA 1995;273:408-412.

19 Wood L, Egger M, Gluud LL, Schulz KF, Jüni P, Altman DG, et al. Empirical evidence of bias in treatment effect estimates in controlled trials with different interventions and outcomes: meta-epidemiological study. BMJ 2008;336:601-605.

20 West S, King V, Carey TS, Lohr KN, McKoy N, Sutton SF, et al. Systems to rate the strength of scientific evidence. Evid Rep Technol Assess (Summ) 2002;47:1-11.

21 Hozo SP, Djulbegovic B, Hozo I. Estimating the mean and variance from the median, range, and the size of a sample. BMC Med Res Methodol 2005;5:13.

22 DerSimonian R, Laird N. Meta-analysis in clinical trials. Control Clin Trials 1986;7:177-188.

23 Borenstein M, Higgins JP, Hedges LV, Rothstein HR. Basics of meta-analysis: I2 is not an absolute measure of heterogeneity. Res Synth Methods 2017;8:5-18.

24 Higgins JP, Thompson SG. Quantifying heterogeneity in a meta-analysis. Stat Med 2002;21:1539-1558.

25 Higgins JP. Commentary: Heterogeneity in meta-analysis should be expected and appropriately quantified. Int J Epidemiol 2008;37:1158-1160.

26 Newell DJ. Intention-to-treat analysis: implications for quantitative and qualitative research. Int J Epidemiol 1992;21:837-841.

27 Sweeting MJ, Sutton AJ, Lambert PC. What to add to nothing? Use and avoidance of continuity corrections in meta-analysis of sparse data. Stat Med 2004;23:1351-1375.

28 Macaskill P, Walter SD, Irwig L. A comparison of methods to detect publication bias in 
meta-analysis. Stat Med 2001;20:641-654.

29 Sterne JA, Egger M. Funnel plots for detecting bias in meta-analysis: guidelines on choice of axis. J Clin Epidemiol 2001;54:1046-1055.

30 Egger M, Davey Smith G, Schneider M, Minder C. Bias in meta-analysis detected by a simple, graphical test. BMJ 1997;315:629-634.

31 Ducerf C, Mechet I, Landry JL, DeLaRoche E, Berthoux N, Bourdeix O, et al. Hemodynamic profiles during piggyback liver grafts using arterial or portal revascularization. J Am Coll Surg 2000;190:89-93.

32 Moreno C, Sabaté A, Figueras J, Camprubí I, Dalmau A, Fabregat J, et al. Hemodynamic profile and tissular oxygenation in orthotopic liver transplantation: Influence of hepatic artery or portal vein revascularization of the graft. Liver Transpl 2006;12:1607-1614.

33 Sankary HN, McChesney L, Frye E, Cohn S, Foster P, Williams J. A simple modification in operative technique can reduce the incidence of nonanastomotic biliary strictures after orthotopic liver transplantation. Hepatology 1995;21:63-69.

34 Massarollo PC, Mies S, Raia S. Simultaneous arterial and portal revascularization in liver transplantation. Transplant Proc 1998;30:2883-2884.

35 Lu D, Xu X, Wang J, Ling Q, Xie H, Zhou L, et al. The influence of a contemporaneous portal and hepatic artery revascularization protocol on biliary complications after liver transplantation. Surgery 2014;155:190-195.

36 Baccarani U, Rossetto A, Lorenzin D, Bidinost S, Pertoldeo ML, Lugano M, et al. Protection of the intrahepatic biliary tree by contemporaneous portal and arterial reperfusion: results of a prospective randomized pilot study. Updates Surg 2012;64:173177.

37 Polak WG, Porte RJ. The sequence of revascularization in liver transplantation: it does make a difference. Liver Transpl 2006;12:1566-1570.

38 Walsh TS, Garden OJ, Lee A. Metabolic, cardiovascular, and acid-base status after hepatic artery or portal vein reperfusion during orthotopic liver transplantation. Liver Transpl 2002;8:537-544.

39 Millis JM, Melinek J, Csete M, Imagawa DK, Olthoff KM, Neelankanta G, et al. Randomized controlled trial to evaluate flush and reperfusion techniques in liver transplantation. Transplantation 1997;63:397-403.

40 Zhu XH, Pan JP, Wu YF, Ding YT. Effects of warm ischemia time on biliary injury in rat liver transplantation. World J Gastroenterol 2012;18:6308-6314. 
41 Zhu XH, Pan JP, Wu YF, Ding YT. Establishment of a rat liver transplantation model with prolonged biliary warm ischemia time. World J Gastroenterol 2012;18:7194-7200.

42 Levesque E, Duclos J, Ciacio O, Adam R, Castaing D, Vibert E. Influence of larger graft weight to recipient weight on the post-liver transplantation course. Clin Transplant 2013;27:239-247.

43 Wang JZ, Liu Y, Wang JL, Lu L, Zhang YF, Lu HW, et al. Sequential vs simultaneous revascularization in patients undergoing liver transplantation: A meta-analysis. World $\mathbf{J}$ Gastroenterol 2015;21:7036-7046.

44 Adani GL, Rossetto A, Lorenzin D, Lugano M, De Anna D, Della Rocca G, et al. Sequential versus contemporaneous portal and arterial reperfusion during liver transplantation. Transplant Proc 2011;43:1107-1109.

45 Wu DG, Zheng SG, Dong JH, Wang SG, Bie P. Comparative study of two intraoperative reperfusion modes affecting liver function at the early stage after orthotopic liver transplantation. J Dig Surg 2006;3:175-178. 


\section{Table 1}

Details of the search strategy and the accessed databases

\begin{tabular}{|c|c|c|}
\hline Database & Period & Search terms \\
\hline PubMed & $\begin{array}{l}\text { December } 2014 / \text { updated } \\
\text { August } 2015 / \text { Updated } \\
\text { December } 2016\end{array}$ & $\begin{array}{l}\text { (Sequential OR simultaneous OR } \\
\text { contempor*) AND (reperfusion OR } \\
\text { perfusion) AND (liver transplant*) } \\
23 \text { articles }\end{array}$ \\
\hline Embase & $\begin{array}{l}\text { April 2015/ Updated } \\
\text { December } 2016\end{array}$ & $\begin{array}{l}\text { (Sequential OR simultaneous OR } \\
\text { contempor*) AND (reperfusion OR } \\
\text { perfusion) AND (liver transplant*) } \\
18 \text { articles }\end{array}$ \\
\hline Medline & $\begin{array}{l}\text { April 2015/ Updated } \\
\text { November } 2016\end{array}$ & $\begin{array}{l}\text { (Sequential OR simultaneous OR } \\
\text { contempor*) AND (reperfusion OR } \\
\text { perfusion) AND (liver transplant*) } \\
63 \text { articles }\end{array}$ \\
\hline Ovid & $\begin{array}{l}\text { April 2015/ Updated } \\
\text { December } 2016\end{array}$ & $\begin{array}{l}\text { 1. (Sequential OR simultaneous OR } \\
\text { contempor*) AND (reperfusion } \\
\text { OR perfusion) AND (liver } \\
\text { transplant*) } \\
\text { 2. Sequential versus simultaneous } \\
\text { hepatic reperfusion } \\
36 \text { articles }\end{array}$ \\
\hline Trip database & $\begin{array}{l}\text { May 2015/updated } \\
\text { December } 2016\end{array}$ & $\begin{array}{l}\text { (Sequential OR simultaneous OR } \\
\text { contempor*) AND (reperfusion OR } \\
\text { perfusion) AND (liver transplant*) } \\
172 \text { articles }\end{array}$ \\
\hline Web of Science & $\begin{array}{l}\text { December } 2014 / \text { updated } \\
\text { July } 2015 / \text { second update } \\
\text { November } 2016\end{array}$ & $\begin{array}{l}\text { (Sequential OR simultaneous OR } \\
\text { contempor*) AND (reperfusion OR } \\
\text { perfusion) AND (liver transplant*) } \\
59 \text { articles }\end{array}$ \\
\hline Cochrane database & $\begin{array}{l}\text { May 2015/ updated } \\
\text { December } 2016\end{array}$ & $\begin{array}{l}\text { (Sequential OR simultaneous OR } \\
\text { contempor*) AND (reperfusion OR } \\
\text { perfusion) AND (liver transplant*) } \\
13 \text { articles }\end{array}$ \\
\hline
\end{tabular}




\section{Table 2}

Summary of study characteristics

\begin{tabular}{|c|c|c|c|c|c|c|c|c|}
\hline \multirow{2}{*}{ Studies } & \multirow{2}{*}{$\begin{array}{l}\text { Sample } \\
\text { size }\end{array}$} & \multirow{2}{*}{ Study design } & \multirow{2}{*}{$\begin{array}{l}\text { Total } \\
\text { study } \\
\text { quality } \\
\text { scoring }\end{array}$} & \multicolumn{2}{|c|}{$\begin{array}{l}\text { Standard } \\
\text { reperfusion }\end{array}$} & \multicolumn{2}{|c|}{$\begin{array}{l}\text { Contemporaneous } \\
\text { reperfusion }\end{array}$} & \multirow{2}{*}{$\begin{array}{l}\text { Follow-up } \\
\text { (mon, } \\
\text { median, } \\
\text { range) }\end{array}$} \\
\hline & & & & $\begin{array}{l}\text { Gender } \\
(\mathrm{M} / \mathrm{F})\end{array}$ & $\begin{array}{l}\text { Age }(y r, \text { mean } \\
\pm \mathrm{SD} / \text { range })\end{array}$ & $\begin{array}{l}\text { Gender } \\
(\mathrm{M} / \mathrm{F})\end{array}$ & $\begin{array}{l}\text { Age (yr, mean } \\
\pm \mathrm{SD} / \text { range })\end{array}$ & \\
\hline Sankary et al 1995 [33] & 131 & $\begin{array}{c}\text { Retrospective } \\
\text { case-control }\end{array}$ & 34 & - & $46.6 \pm 14$ & - & $49 \pm 15$ & 4 \\
\hline Massarollo et al 1998 [34] & 76 & $\begin{array}{c}\text { Retrospective } \\
\text { case-control }\end{array}$ & 25 & $16 / 10$ & $39.7 \pm 13.6$ & $36 / 14$ & $40 \pm 13$ & $24-60$ \\
\hline Ducerf et al 2000 [31] & 59 & $\mathrm{RCT}$ & 28 & $19 / 11$ & $49 \pm 6$ & $20 / 9$ & $51 \pm 10$ & 34 \\
\hline Polak et al 2005 [13] & 102 & $\begin{array}{l}\text { Prospective } \\
\text { case-control }\end{array}$ & 23 & $45 / 26$ & $46(18-65)$ & $18 / 13$ & $46(17-63)$ & 12 \\
\hline Moreno et al 2006 [32] & 60 & $\mathrm{RCT}$ & 30 & $18 / 12$ & $55(36-67)$ & $24 / 6$ & $53(36-68)$ & 1 \\
\hline Baccarani et al 2012 [36] & 80 & $\mathrm{RCT}$ & 30 & $29 / 9$ & $56 \pm 7$ & $31 / 11$ & $56 \pm 12$ & 6 \\
\hline Lu et al 2014 [35] & 177 & $\begin{array}{c}\text { Retrospective } \\
\text { case-control }\end{array}$ & 26 & $50 / 6$ & $47 \pm 11$ & $103 / 18$ & $48 \pm 9$ & 24 \\
\hline
\end{tabular}




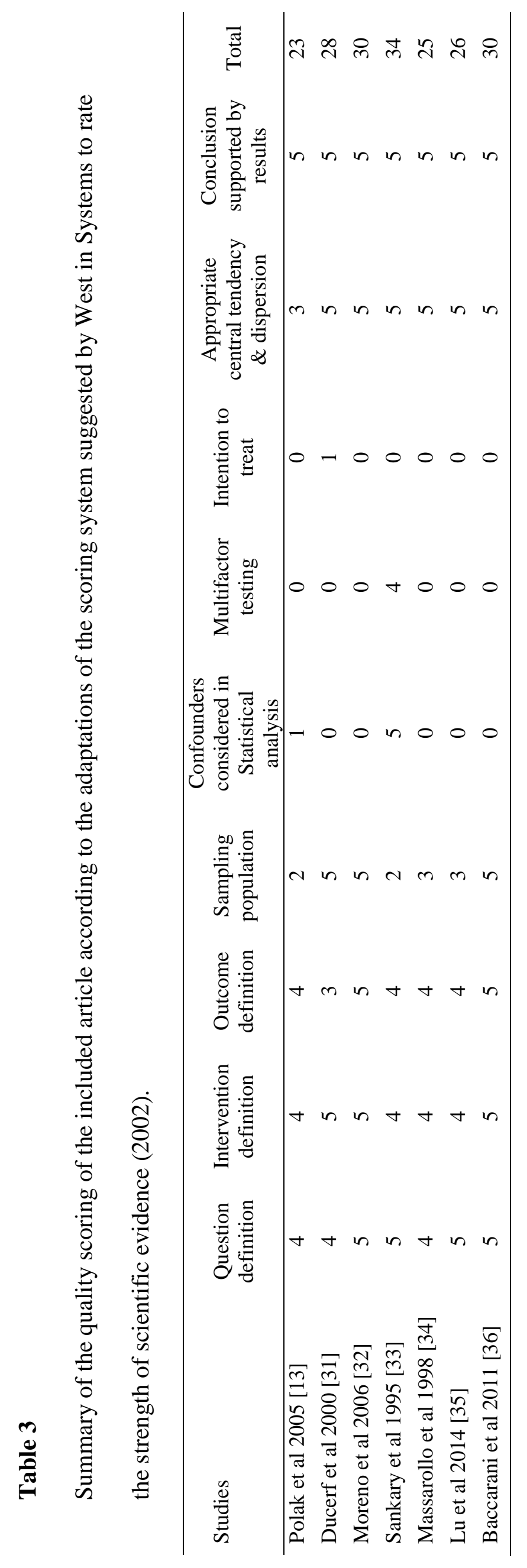




\section{Figures Legend}

Fig. 1. PRISMA chart illustrating the filtration process of the included studies.

Fig. 2A: The forest plot demonstrates no significant difference between simultaneous reperfusion - compared to the sequential one - on the prevalence of non-anastomotic biliary stricture (NABST); B-D: Subgroup analyses by study design, study date and study quality score.

Fig. 3A: Forest plot demonstrating a similar incidence of pooled Clavien grade complications in the simultaneous reperfusion group compared to the sequential reperfusion group; $\mathbf{B}$ : Forest plot demonstrating the higher prevalence of the Clavien-Dindo II grade complications in the simultaneous reperfusion compared to the sequential reperfusion group. C: Forest plot demonstrating the equal prevalence of the Clavien-Dindo IV grade complications in both groups.

Fig. 4. Funnel plot for visual depiction of publication bias. 
Random

$\begin{array}{ll}\text { Ducerf et al 2000 } & \text { NABST } \\ \text { Moreno et al 2006 } & \text { NABST } \\ \text { Sankary et al 1995 } & \text { NABST } \\ \text { Massarollo et al 1998 } & \text { NABST } \\ \text { Polak et al 2005 } & \text { NABST } \\ \text { Lu et al 2014 } & \text { NABST } \\ \text { Baccarani et al 2012 } & \text { NABST }\end{array}$

Lower Odds Upper

limit ratio limit IAR-SIM IPR $P$ value

$\begin{array}{lrrlll}0.11 & 0.92 & 7.62 & 2 / 15 & 2 / 14 & 0.94 \\ 0.25 & 5.35 & 116.31 & 2 / 30 & & 0.29 \\ 0.03 & 0.25 & 2.07 & 1 / 45 & 7 / 83 & 0.20 \\ 0.01 & 0.17 & 4.28 & & 1 / 26 & 0.28 \\ 0.38 & 1.79 & 8.55 & 3 / 31 & 4 / 71 & 0.46 \\ 0.02 & 0.09 & 0.42 & 2 / 121 & 9 / 56 & 0.00 \\ 0.00 & 0.05 & 0.82 & & 9 / 42 & 0.04 \\ 0.12 & 0.40 & 1.37 & & & 0.14\end{array}$

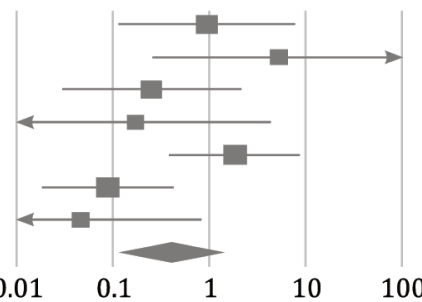

Favours IAR/Sim-R Favours IPR

Heterogeneity: overall $I^{2}=54 \%$

\begin{tabular}{|c|c|c|c|c|c|c|c|c|c|}
\hline \multirow[t]{6}{*}{ Model } & \multirow{2}{*}{$\begin{array}{l}\text { Group by } \\
\text { Study quality } \\
\text { score }\end{array}$} & \multirow[t]{2}{*}{ Study name } & \multicolumn{2}{|c|}{ Comparison } & \multicolumn{3}{|c|}{ Events/Total } & \multirow[b]{2}{*}{ IPR } & \multirow[b]{2}{*}{$P$ value } \\
\hline & & & & $\begin{array}{l}\text { Lower } \\
\text { limit }\end{array}$ & $\begin{array}{l}\text { Odds } \\
\text { ratio }\end{array}$ & $\begin{array}{c}\text { Upper } \\
\text { limit }\end{array}$ & IAR-SIM & & \\
\hline & $<30$ & Ducerf et al 2000 & NABST & 0.11 & 0.92 & 7.62 & $2 / 15$ & $2 / 14$ & 0.94 \\
\hline & $<30$ & Lu et al 2014 & NABST & 0.02 & 0.09 & 0.42 & $2 / 121$ & $9 / 56$ & 0.00 \\
\hline & $<30$ & Massarollo et al 1998 & NABST & 0.01 & 0.17 & 4.28 & $1 / 31$ & $1 / 26$ & 0.28 \\
\hline & $<30$ & Polak et al 2005 & NABST & 0.38 & 1.79 & 8.55 & & $4 / 71$ & 0.46 \\
\hline Random & $<30$ & & & 0.08 & 0.43 & 2.16 & $2 / 30$ & & 0.30 \\
\hline & $\geq 30$ & Baccarani et al 2012 & NABST & 0.00 & 0.05 & 0.82 & 1/ 45 & $9 / 42$ & 0.04 \\
\hline & $\geq 30$ & Moreno et al 2006 & NABST & 0.25 & 5.35 & 116.31 & & & 0.29 \\
\hline & $\geq 30$ & Sankary et al 1995 & NABST & 0.03 & 0.25 & 2.07 & & $7 / 83$ & 0.20 \\
\hline m & $\geq 30$ & & & 0.03 & 0.36 & 4.17 & & & 0.41 \\
\hline Random & Overall & & & 0.11 & 0.41 & 1.57 & & & 0.19 \\
\hline
\end{tabular}

\section{Odds ratio and $95 \% \mathrm{CI}$}

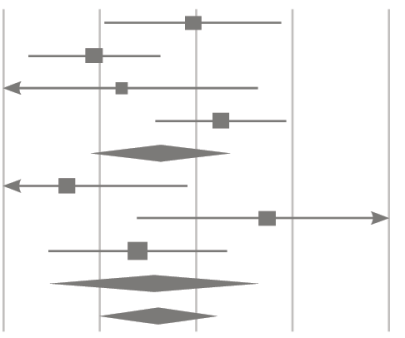

$\begin{array}{lllll}0.01 & 0.1 & 1 & 10 & 100\end{array}$ Favours IAR/Sim-R Favours IPR

Heterogeneity: > 30; $I^{2}=60 \% ; \geq 30: I^{2}=62 \%$; overall: $I^{2}=54 \%$

\begin{tabular}{|c|c|c|c|c|c|c|c|c|c|}
\hline \multirow{2}{*}{ Model } & \multirow{2}{*}{ 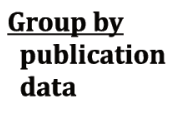 } & \multirow[t]{2}{*}{ Study name } & \multicolumn{2}{|c|}{ omparison } & \multicolumn{3}{|c|}{ Events/Total } & \multirow[b]{2}{*}{ IPR } & \multirow[b]{2}{*}{$P$ value } \\
\hline & & & & $\begin{array}{c}\text { Lower } \\
\text { limit }\end{array}$ & $\begin{array}{l}\text { Odds } \\
\text { ratio }\end{array}$ & $\begin{array}{c}\text { Upper } \\
\text { limit }\end{array}$ & IAR-SIM & & \\
\hline & $<2005$ & Ducerf et al 2000 & NABST & 0.11 & 0.92 & 7.62 & $2 / 15$ & $2 / 14$ & 0.94 \\
\hline & $<2005$ & Massarollo et al 1998 & NABST & 0.01 & 0.17 & 4.48 & & $1 / 26$ & 0.28 \\
\hline & $<2005$ & Sankary et al 1995 & NABST & 0.03 & 0.25 & 2.07 & $1 / 45$ & $7 / 83$ & 0.20 \\
\hline Random & $<2005$ & & & 0.10 & 0.40 & 1.55 & & & 0.19 \\
\hline & $\geq 2005$ & Baccarani et al 2012 & NABST & 0.00 & 0.05 & 0.82 & & $9 / 42$ & 0.04 \\
\hline & $\geq 2005$ & Lu et al 2014 & NABST & 0.02 & 0.09 & 0.42 & $2 / 121$ & $9 / 56$ & 0.00 \\
\hline & $\geq 2005$ & Moreno et al 2006 & NABST & 0.25 & 5.35 & 116.31 & $2 / 30$ & & 0.29 \\
\hline & $\geq 2005$ & Polak et al 2005 & NABST & 0.38 & 1.79 & 8.55 & $3 / 31$ & $4 / 71$ & 0.46 \\
\hline & $\geq 2005$ & & & 0.05 & 0.42 & 3.55 & & & 0.43 \\
\hline Random & Overall & & & 0.13 & 0.41 & 1.28 & & & 0.12 \\
\hline
\end{tabular}

Heterogeneity: < 2005: $I^{2}=0 \%$; $\geq 2005: I^{2}=75 \%$; overall: $I^{2}=54 \%$

Model Group by study design

Comparative studies Lu et al 2014

Comparative studies Massarollo et a

Comparative studies Polak et al 2005

Comparative studies Sankary et al 1995

Comparative studies

RCT

RCT

RCT

Random RCT

Random Overall

Ducerf et al 2000

Moreno et al 2006

\section{Study name \\ Comparison}

Lower Odds Upper

limit ratio limit IAR-SIM IPR $P$ value

NABST

NABST

NABST

NABST

Baccarani et al 2012

NABST

NABST

NABST

$\begin{array}{lrrrrr}0.02 & 0.09 & 0.42 & 2 / 121 & 9 / 56 & 0.00 \\ 0.01 & 0.17 & 4.28 & & 1 / 26 & 0.28 \\ 0.38 & 1.79 & 8.55 & 3 / 31 & 4 / 71 & 0.46 \\ 0.03 & 0.25 & 2.07 & 1 / 45 & 7 / 83 & 0.20 \\ 0.06 & 0.31 & 1.50 & & & 0.15 \\ 0.00 & 0.05 & 0.82 & & 9 / 42 & 0.04 \\ 0.11 & 0.92 & 7.62 & 2 / 15 & 2 / 14 & 0.94 \\ 0.25 & 5.35 & 116.31 & 2 / 30 & & 0.29 \\ 0.05 & 0.61 & 7.19 & 3 / 31 & & 0.69 \\ 0.10 & 0.38 & 1.42 & & & 0.15\end{array}$

Heterogeneity: comparative studies: $I^{2}=60 \%$; RCT: $I^{2}=61 \%$; overall: $I^{2}=54 \%$ 


\section{Random}

Lu et al 2014

\section{Comparison}

Lower Odds Upper

limit ratio limit IAR-SIM IPR $P$ value

Ducerf et al 2000

Moreno et al 2006

Polak et al 2005
Clavien_IV_a

Clavien_II

Combined

Combined

$\begin{array}{rrrrrr}0.02 & 0.26 & 2.88 & 1 / 15 & 3 / 14 & 0.27 \\ 0.18 & 2.07 & 24.15 & 2 / 30 & 1 / 30 & 0.56 \\ 0.30 & 1.40 & 6.60 & 4 / 31 & 5 / 71 & 0.67 \\ 0.08 & 0.49 & 2.97 & 40 / 121 & 17 / 56 & 0.44 \\ 0.32 & 0.83 & 2.20 & & & 0.71\end{array}$

Odds ratio and $95 \%$ CI

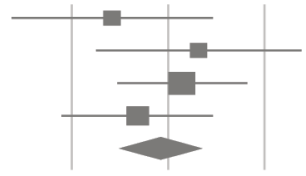

$10 \quad 100$

Heterogeneity: $I^{2}=0 \%$

Favours IAR/Sim-R Favours IPR

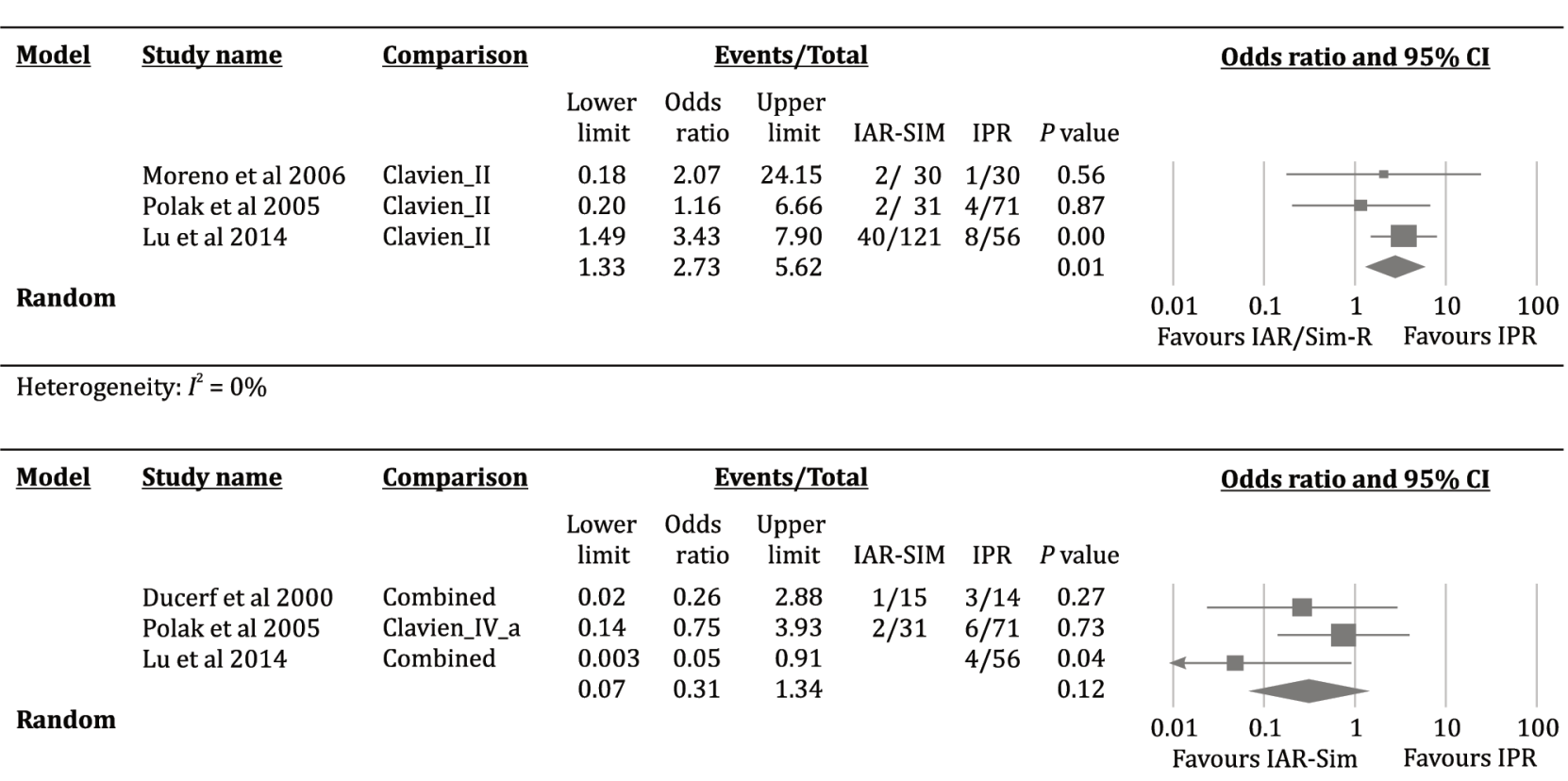

Heterogeneity: $I^{2}=23 \%$ 
Funnel plot of standard error by log odds ratio

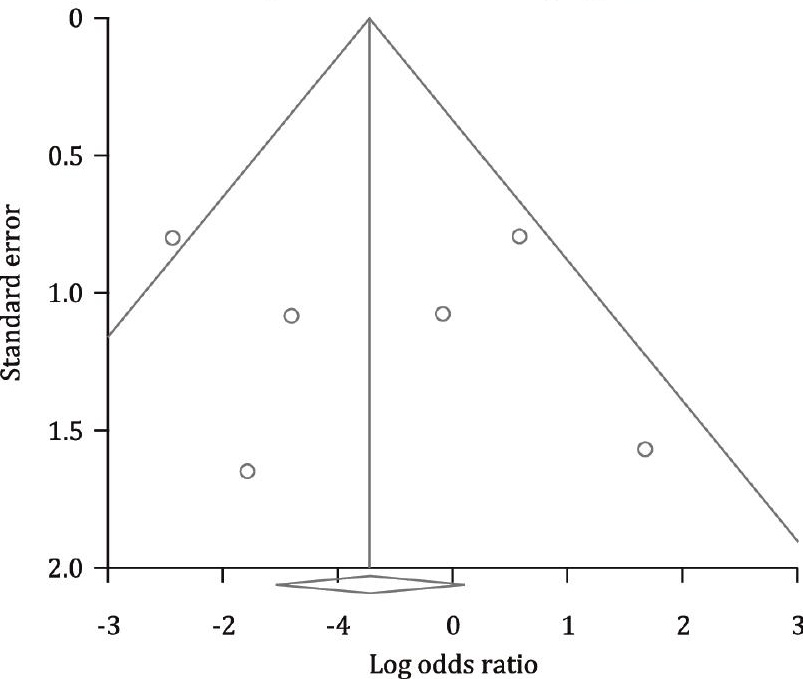

